\title{
Bulblet Differentiation after Scale Propagation of Lilium longiflorum
}

\author{
Pablo A. Marinangeli, Luis F. Hernández, Cecilia P. Pellegrini, and Néstor R. Curvetto \\ Departamento de Agronomía, Universidad Nacional del Sur. CERZOS, CONICET, San Andrés 800, 8000 \\ Bahía Blanca, Argentina
}

ADDitional INDEX wORDs. lily, developmental stages, scaling

\begin{abstract}
External, middle and inner scales in parent bulbs were studied to evaluate bulblet differentiation in Lilium longiflorum Thunb. during scale propagation at $25^{\circ} \mathrm{C}$. A 13-stage developmental process describes different steps including preprimordial, primordial, and bulblet formation. For all scales, preprimordial and primordial stages occurred within the first 4 days. The differentiation process depended on parent scale position. Most bulblets arising from external scales developed three true scales after $\mathbf{3 0}$ days while bulblets from middle scales formed four true scales. Homogeneity in the morphology of the parent scales, only shown in the middle ones, was associated with a rapid change in developmental stage for the population of bulblets. Inner scales showed few bulblets with three and four true scales, the rest remaining at earlier developmental stages. Bulblet production decreased from external to internal scales: 2.6, 2.2, and 1.2 bulblets per scale, respectively, and showed a positive correlation with the scale base width. Maximum scale weight and surface area and maximum bulblet fresh and dry weight occurred in the middle scales. We conclude that middle scales are the ideal starting material for experimental uses involving scaling propagation. For production purposes, the external scales, in addition to the middle scales, must also be included for propagation.
\end{abstract}

Lily bulb growth and development has been well decribed previously (Roberts et al., 1985). Scales of two ages can be clearly distinguished in a Lilium longiflorum Thunb. bulb before it sprouts. Younger scales appear as a rosette and form during the previous growing season at the scar left by the floral stalk. A new floral stem will develop during the coming season from a central meristem in the rosette. These scales arise from an activated bud at the axil of a bract at the stem base (Miller, 1993).

During scaling and in vitro propagation of Lilium from bulbscales, differentiation is completed after approximately four weeks. By that time, little bulbs (bulblets) containing few scales have formed.

In Lilium, the variability within scales of a particular bulb should be known because standardized methods are needed to reduce the variation within treatments when assaying for propagation experiments. Differences in scale weight of Lilium have been reported among the scales of a bulb and between scales from bulbs of different size (Magnani et al., 1990). Larger scales produce more bulblets of greater weight than smaller ones (Matsuo et al., 1987; Matsuo and Van Tuyl, 1986). In Narcissus, the number and size of differentiated bulblets are influenced by the relative position of starting scales in the bulb using the twin-scale technique (Hanks, 1985).

For laboratory and field experiments on Lilium bulblet formation it is important to clearly recognize different developmental stages of bulblets. Stages of plant development have been described for many species of agronomic interest such as wheat (Triticum aestivum) (Tottman et al., 1979) and sunflower (Helianthus annus) (Marc and Palmer, 1981; Schneiter and Miller, 1981). In addition, identifying significant stages in bulblet differentiation will help to standardize the technical vocabulary used to describe bulb growth and development.

Although a scaling technique for Lilium propagation was reported and studied many years ago (Magnani et al., 1990; Matsuo

Received for publication 30 Sept. 2002. Accepted for publication 14 Jan. 2003. This research was supported by the Secretaría de Ciencia y Tecnología, UNS, the Consejo Nacional de Investigaciones Científicas y Técnicas (CONICET) and the Comisión de Investigaciones Científicas de la Provincia de Buenos Aires (CIC). We thank Silvia Delmastro for technical assistance and Jaap Van Tuyl and Débora Figlas for critical reading of the manuscript. et al., 1987; Matsuo and Van Tuyl, 1986) and morphology and development of Lilium longiflorum bulb has been thoroughly described (Miller, 1992; 1993; Roberts et al., 1985), neither a complete study of the scale position in the bulb, morphology and bulbing potential, nor a description of the bulblet development process has been made.

The purpose of our work was to provide 1) a classification of scales according to their position in the bulb and their morphological characteristics, and 2) a description of morphological changes through time during the differentiation of bulblets from bulb scales of Lilium longiflorum. A developmental stage description was performed according to the relative position and age of scales. A classification of scales was developed and its morphological characteristics, such as fresh and dry weight, basal width, height and surface area were correlated with the production of bulblets.

\section{Materials and Methods}

Bulbs of Lilium longiflorum 'Snow Queen' (size 14 to 16) were obtained from our experimental field at Bahía Blanca, Argentina $\left(38^{\circ} 42^{\prime} \mathrm{S}, 62^{\circ} 10^{\prime} \mathrm{W}\right)$. Bulbs were stored at $4^{\circ} \mathrm{C}$ for 2 months. For each experiment, scales were removed, washed in tap water, and immersed in a sodium hypochloride solution $(0.8 \%$ active chlorine plus $0.01 \%(\mathrm{v} / \mathrm{v})$ Tween 20) for $10 \mathrm{~min}$. Scales were then washed three times in distilled water and treated for $60 \mathrm{~min}$ with $0.1 \%$ (w/v) Benomyl (Benlate WP50\%, methyl 1-butylcarbamoyl2-benzimidazole carbamate) and transferred to humid chambers $(\mathrm{RH}>95 \%)$ at $25^{\circ} \mathrm{C}$ in darkness with their basal ends in contact with moistened filter paper.

Two groups of scales were cultivated: one for a kinetic study of bulblet differentiation and the evaluation of the influence of bulb scale position, and the other for a morphological study of bulblet differentiation.

GROUP I: KiNETIC STUDY OF BULBLET DIFFERENTIATION AND PaRENTAL-SCALE POSITION Influence. The fresh weight of five whole bulbs, their scales and their basal disks with sprouts were recorded. The scales of each bulb, scored as external, middle and inner, were separated, identified, and placed into a humid chamber 
Table 1. Average fresh weight of a Lilium longiflorum bulb (size 14 to 16), their parts and average number of scales. Fresh weight partition in percentage is indicated.

\begin{tabular}{|c|c|c|c|c|}
\hline & \multirow[b]{2}{*}{ No. } & \multirow[b]{2}{*}{ Fresh wt (g) } & \multicolumn{2}{|c|}{ Fresh wt (\%) } \\
\hline & & & $\%$ of total scales & $\%$ of total bulb \\
\hline External scales & $10.7(6.0) \mathbf{b}^{z}$ & $8.96(0.46) \mathbf{b}$ & 29.5 & 24.5 \\
\hline Middle scales & $16.3(2.5) \mathbf{a}$ & $17.79(0.48) \mathbf{a}$ & 58.6 & 48.5 \\
\hline Total scales & $34.0(8.7)$ & $30.35(4.62)$ & 100.0 & 82.8 \\
\hline Basal disc + sprout & --- & $6.31(1.92)$ & --- & 17.2 \\
\hline Total bulb & --- & $36.66(5.36)$ & --- & 100.0 \\
\hline
\end{tabular}

$\bar{z}$ Values in brackets represent the mean standard deviation. Mean values followed by different letter in each column differ significantly $(P \leq 0.05)$ according to Tukey-Kramer test.

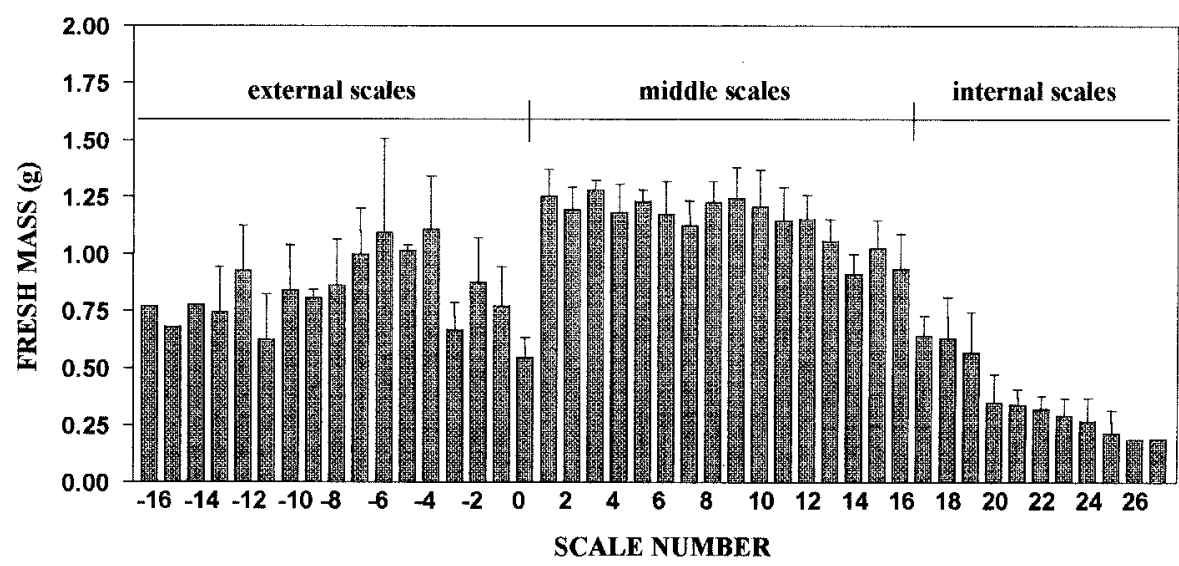

Fig. 1. Lilium longiflorum scales average fresh weight presented according to their location in the bulb. Lines on the bars indicate the standard error of the media.

as mentioned above. Morphological changes were recorded daily until full bulblet development. The inner area of the scales was estimated using the equation $1 / 2$ B.H, where B is the base width, and $\mathrm{H}$ is the height of scales. Dry weight of scales was obtained at the end of the assay.

Bulblets were harvested after $30 \mathrm{~d}$ and the stage of morphological development was recorded. Transverse diameter, as the mean of the maximum and the minimum transverse diameter, fresh weight, and dry weight were also measured.

A randomized complete-block design was used, with each bulb as a block and scale position as the treatment. ANOVA tests for statistical difference at the $P \leq 0.05$ level were performed. Comparison of mean values was done using the Tukey-Kramer test (Ott, 1984).

GrouP II: IDENTIFICATION OF SIGNIFICANT MORPHOLOGICAL STAGES IN BULBLET DIFFERENTIATION. Scales were cultivated to fix some of them in each developmental stage. Three hundred scales were kept in six humid chambers under the same conditions previously described, and three scales were chosen randomly each day from those representing the morphological stage reached that day by the majority of scales in group I.

Sequential observations of bulblet primordia differentiation were made using the replica method developed by Green and Linstead (1990) and modified for sunflower by Hernández and Green (1993). A mold of each primordium at the scale base was made using a dental polymer (Mirror 3, Kerr Manufacturing Co., Romulus, Mich.) and a Spurr resin cast was obtained. Replicas were mounted on stubs and sputter coated with gold/palladium, then observed at $5 \mathrm{Kv}$ with a scanning electron microscope (JEOL 35-CF).

Transverse sections of a bulblet primordium were also made at the differentiation zone for observation by light microscopy. Sections were stained with $0.5 \%(\mathrm{w} / \mathrm{v})$ Toluidine Blue in acetate buffer, $\mathrm{pH}$ 5.4, observed by light microscopy and photographed. When bulblets were large enough, they were observed in a stereo microscope and photographed.

\section{Results and Discussion}

Classification of Bulb SCALes. In Lilium longiflorum bulbs, older scales formed during the two previous growing seasons supported the sprouting floral stem during the past year. These external scales store assimilates for a second time and enable new sprouting in association with the younger scales. External scales die as the vegetative growing period advances. In the process, some middle scales also die while others, together with inner scales, become the external scales at the end of the growing period, after the new middle

Table 2. Parameters of individual scales according to scale bulb location.

\begin{tabular}{|c|c|c|c|c|}
\hline \multirow[b]{2}{*}{ Parameter } & \multicolumn{3}{|c|}{ Scale position } & \multirow[b]{2}{*}{ Total } \\
\hline & External & Middle & Internal & \\
\hline Initial fresh weight (g) & $0.837(0.29) \mathbf{b}^{\mathbf{z}}$ & $1.163(0.18) \mathbf{a}$ & $0.449(0.24) \mathbf{c}$ & $0.893(0.37)$ \\
\hline Final fresh weight $(\mathrm{g})$ & $0.772(0.27) \mathbf{b}$ & $1.161(0.18) \mathbf{a}$ & $0.472(0.24) \mathbf{c}$ & $0.877(0.36)$ \\
\hline Base width (mm) & $13.8(3.52) \mathbf{a}$ & $11.0(2.27) \mathbf{b}$ & $8.9(1.09) \mathrm{c}$ & $11.3(3.29)$ \\
\hline Height (mm) & $26.2(2.75) \mathbf{c}$ & $31.2(2.53) \mathbf{a}$ & $28.4(2.61) \mathbf{b}$ & $28.67(3.47)$ \\
\hline
\end{tabular}

zValues in brackets represent the mean standard deviation. Mean values followed by different letter in each row differ significantly $(P \leq 0.05)$ according to Tukey-Kramer test. 
Table 3. Stages of bulblet differentiation from Lilium longiflorum identified by recognizable morphological changes.

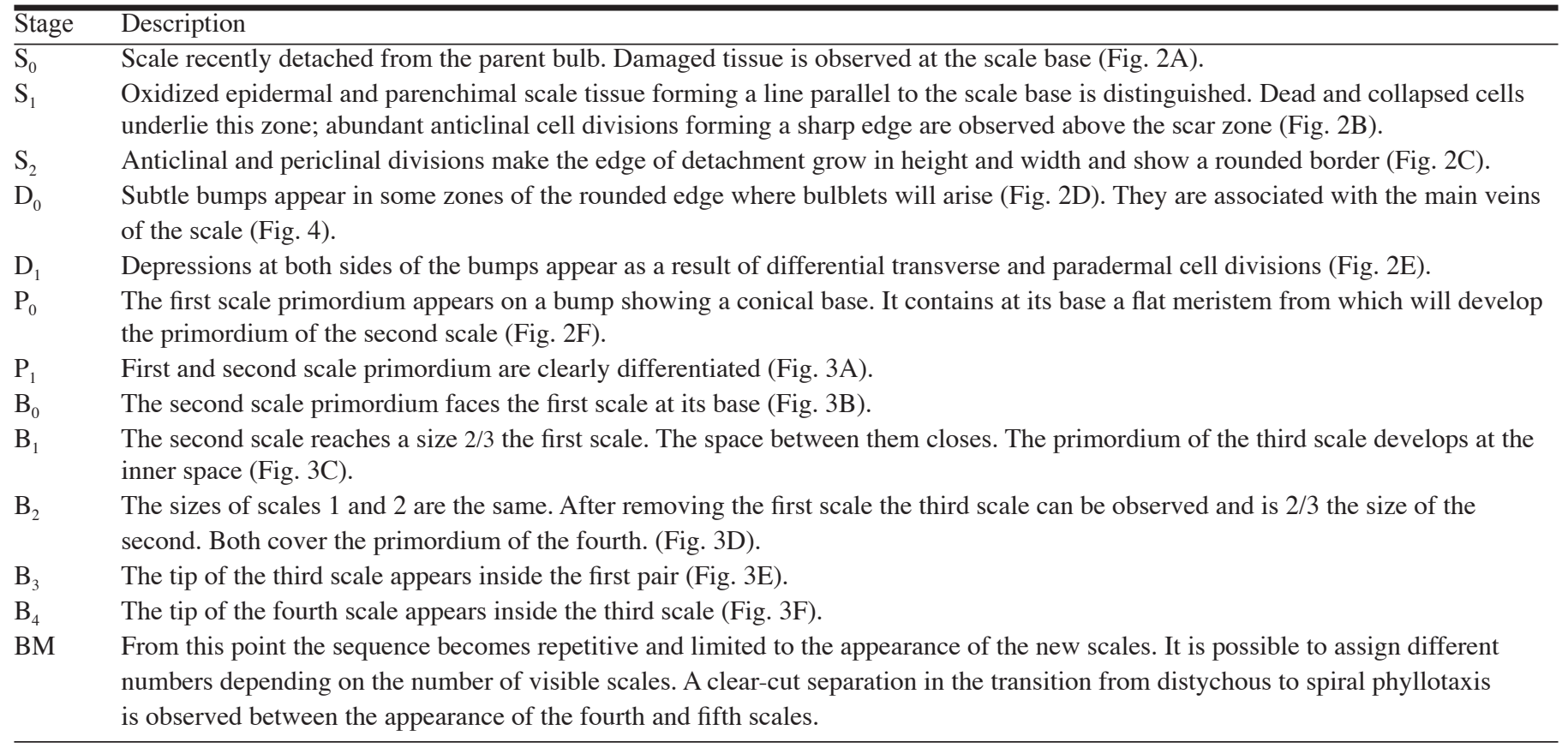

and inner scales are formed. Thus, for a given genotype, the number of external scales is highly variable, probably depending on one or more of these factors: the cultivation and sanitary conditions, the stored food spent during sprouting, and/or the cropping and storage conditions (Table 1). Fresh and dry weight are also highly variable (Fig. 1). The external scales usually appear damaged, and contaminated due to their direct contact with soil and handling during harvest, classification and storage. Frequently, a soft mold or bacterial colonies appear on the damaged surface of external scales (data not shown). In contrast, rosetted or middle scales are less than one year old, they are located more externally in the rosette and appear less damaged and not dehydrated. Scales located around the new sprout were considered internal and they possessed the lowest fresh weight. Their boundary with middle scales is easily recognized because the scales sharply diminish in weight (Fig. 1).

The scale nearest the scar tissue from the floral stalk was considered the initial scale (zero). Numbering followed a centripetal direction, with the last inner scale defined as the one next to the sprout. External scales were numbered negatively in the centrifugal direction starting from the initial scale (Fig. 1) which is easily recognizable because it shows traces of the old floral stalk. It is similar in size to the inner external scales, which constituted the inner scales during the previous season.

About half of the bulb scales were middle ones and

Fig. 2. Developing stages during bulbing in Lilium longiflorum showing the inner basal region of the scale. (A) $\mathrm{S}_{0}$ stage: time of scale removal from the parent bulb $(\times 86)$. (B) $\mathrm{S}_{1}$ stage: edge with cliff appearance (arrow). Cells are collapsed at the bottom (x86). (C) $\mathrm{S}_{2}$ stage: edge with the appearance of a particular smooth elevation (e) along the edge; abundant cell divisions are observed $(x 44)$. (D) $\mathrm{D}_{0}$ stage: bulked structure (b) coincident with the folding of the vein $(\times 54)$. (E) D stage: depressions at both sides of the bulky structure (b) are observed ( $\times 36)$. (F) $\mathrm{P}_{0}$ stage: primordium of the first scale $(\mathbf{p})$ hugs the meristem (m) giving rise to the second scale (x66).
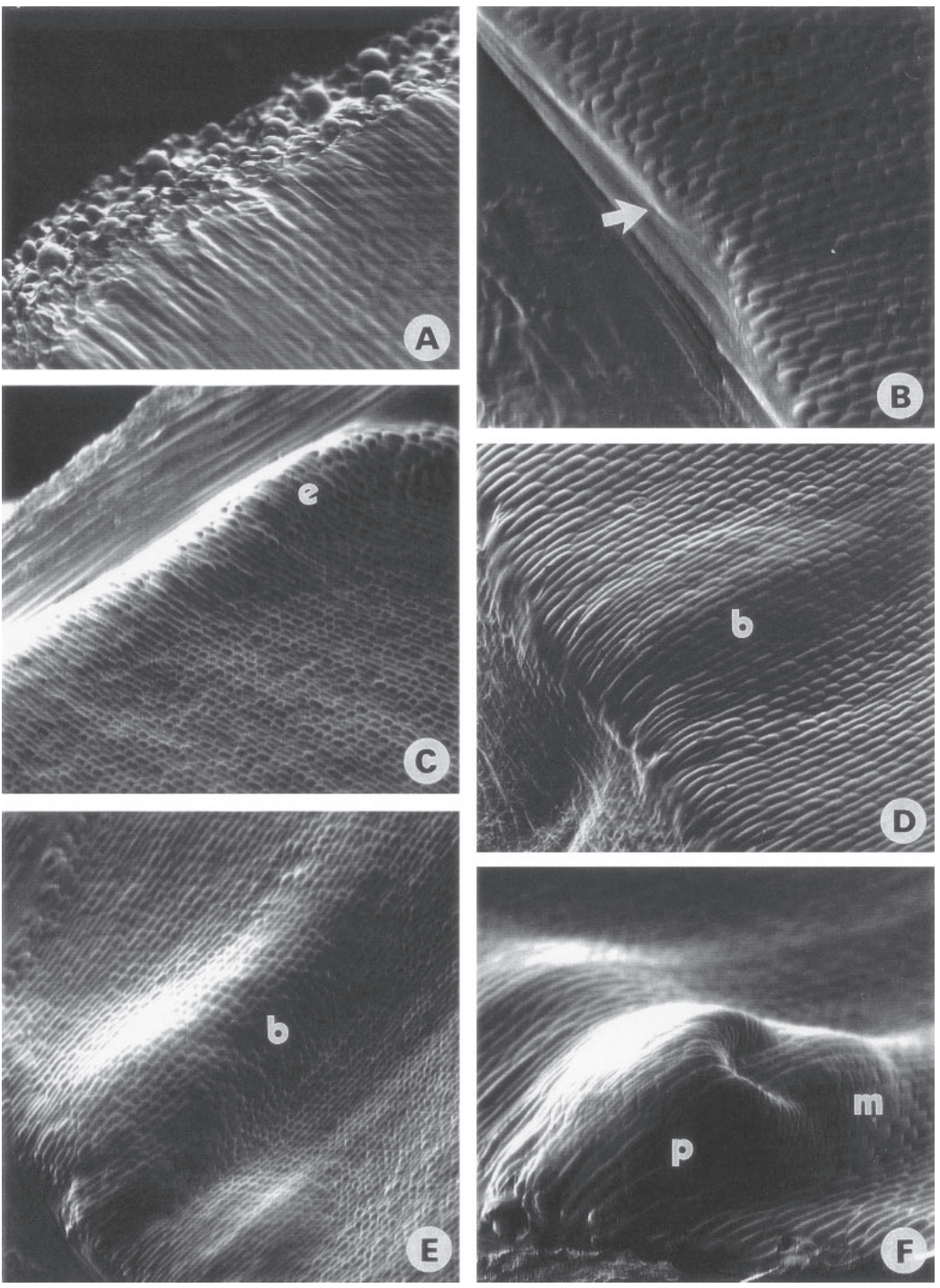

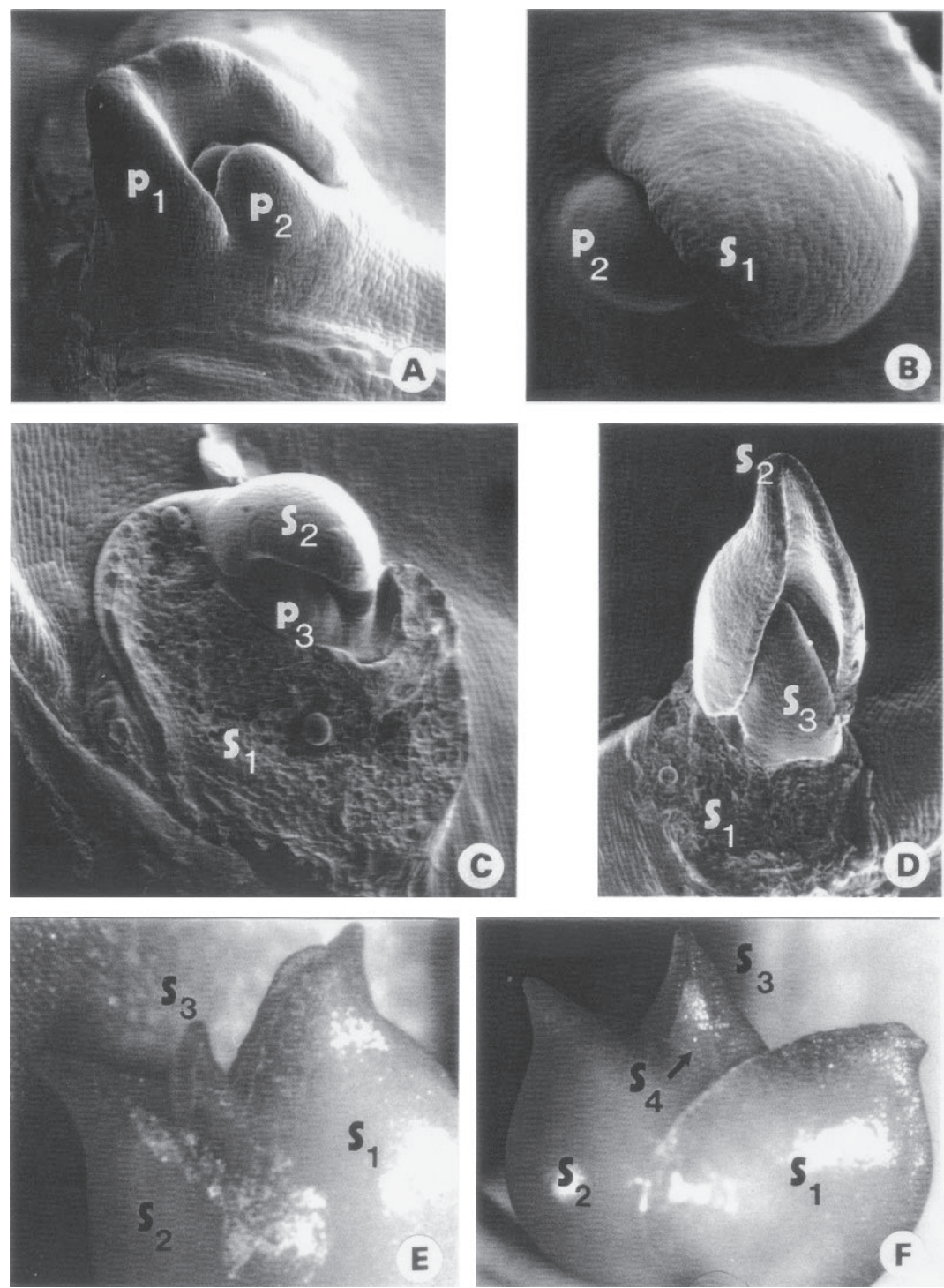

Fig. 3. Developing stages during bulbing in Lilium longiflorum showing the inner basal region of the scale. A) $\mathrm{P}_{1}$ stage: first $\left(\mathbf{p}_{1}\right)$ and second $\left(\mathbf{p}_{2}\right)$ scale in primodial stage (x40). B) $B_{0}$ stage: first scale $\left(\mathbf{s}_{1}\right)$ and primordium of the second one $\left(\mathbf{p}_{2}\right)$ (x66). C) $B_{1}$ stage: second scale $\left(\mathbf{s}_{2}\right) 2 / 3$ size of the first $\left(\mathbf{s}_{1}\right)$. Removing the first scale, the primordium of the third one $\left(\mathbf{p}_{3}\right)$ is observed (x54). D) $\mathrm{B}_{2}$ stage: the first scale $\left(\mathbf{s}_{1}\right)$ was removed. The third scale $\left(\mathbf{s}_{3}\right)$ with $2 / 3$ of the second scale $\left(\mathbf{s}_{2}\right)$ is observed (x60). E) $B_{3}$ stage: the third scale $\left(s_{3}\right)$ is observed between the first ones $\left(s_{1}\right.$ and $\left.s_{2}\right)$. F) $B_{4}$ stage: the fourth scale $\left(s_{4}\right)$ appears between the second $\left(\mathrm{s}_{2}\right)$ and third $\left(\mathrm{s}_{3}\right)$ scales.

their number was more stable than external scales. Middle scales accounted for about $50 \%$ of the total bulb fresh weight and $60 \%$ of the total scales fresh weight (Table 1).

Average fresh and dry weight of each middle scales was significantly higher $(P \leq 0.05)$ than that of inner and external scales (Table $2)$. However, the scale inner surface of middle and external scales were quite similar (Table 2), suggesting that a higher content of nutrients was stored in the middle scales. These scales also exhibited a noticeable constancy in number and in fresh weight compared to external scales (Table 1 and Fig. 1). Although the width of the scale base diminished from the external to the inner scales, scale height was significantly greater in middle scales (Table 2).

MAJOR STAGES OF BULB DEVELOPMENT. Morphological changes during bulblet development are described in Table 3. Stages were identified as follows: $\mathbf{S}=$ morphological changes observed at the whole scale level and in the scale base; $\mathbf{D}=$ appearance of domes in different zones of the scale base; $\mathbf{P}=$ appearance of bulblet primordia; $\mathbf{B}=$ formation of bulblets and the number of scales developed in them.

Figures 2 and 3 show developing stages during bulblet differentiation. About $17 \%$ of the scales also developed bulblets from the inner surface at different positions but always starting from wounded tissue.

As known, bulblet differentiation appeared almost exclusively at the basal end of the adaxial side of the scales, close to the two or four main longitudinal veins (Van Aartrijk et al., 1989). Differentiation of vascular tissue was observed at the $\mathbf{D}_{\mathbf{1}}$ stage on a transverse section parallel to the scale base. A junction of this tissue with the meristematic zone will develop into a bulblet with the subjacent vascular bundle with the main vein of the scale. Cellular activity was noted at the zone where bulblet will develop (Fig. 4). This observation supports findings of Yanagawa and Sakanishi (1980) in several Amaryllidaceae and Liliaceae species, in which scale bulblets arise from epidermal and subepidermal cells at the nearest location to vascular tissue. The idea of bulblet development induction by a nutritional and/or hormonal source-sink gradient is supported by the earlier arising of redifferentiated vascular cells forming a bundle between main vein and bulblet preprimordia.

KINETICS OF THE BULBLET DIFFERENTIATION PROCESS. The time course of bulblet differentiation through the culture period is shown in Fig. 5. Bulblet differentiation began from $\mathbf{S}_{\mathbf{0}}$ and $\mathbf{S}_{1}$, which lasted one and two days, respectively, and all scales were concentrated in those stages. At $\mathbf{D}_{0}$ and subsequent stages the highest number of scales with domes, primordia, and bulblets appeared during the first days of each stage, and gradually changed to an accumulative form toward the end of the culture period. The $\mathbf{B}$ stages from external and middle scales appeared on day eight and remained for the rest of the culture period. The highest degree of differentiation by external scales was labeled $\mathbf{B}_{\mathbf{4}}$ while most of them

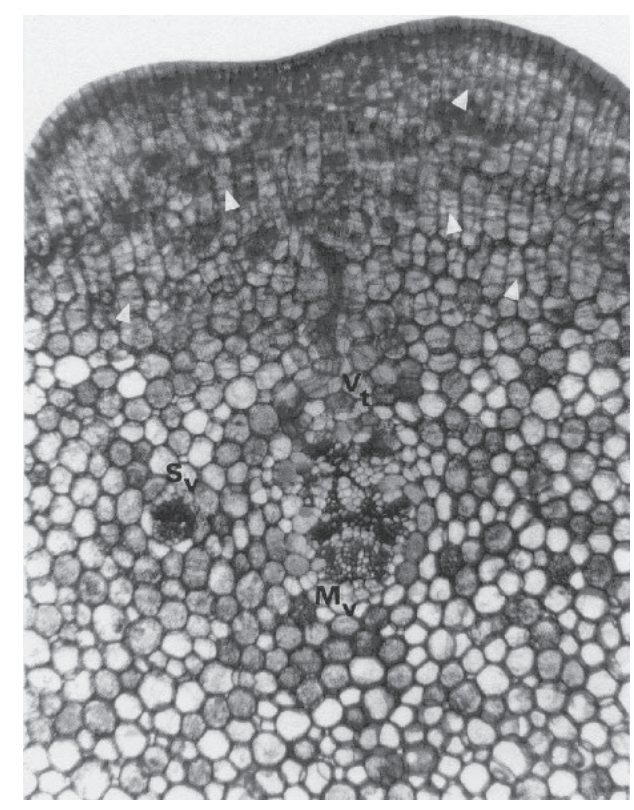
$(46 \%)$ remained at stage $\mathbf{B}_{2}$ (Fig. 6).

Middle scales stages were more concentrated in time, suggesting greater anatomical and physiological homogeneity in differentiation into bulblets. Thus, $\mathbf{B}_{\mathbf{0}}$ and $\mathbf{B}_{1}$ stages disappeared earlier than other stages and some bulblets (2\%) reached the BM stage. Most bulblets reached B $_{3}$ stage $(42 \%)$ as shown in Fig. 6.

Fig. 4. Transverse section parallel to the scale base at the $\mathrm{D}_{1}$ stage. Mv: main scale vein; $\mathbf{S v}$ : secondary scale vein; Vt: differentiating vascular tissue. Arrows show anticlinal and periclinal divisions at the subepidermal level. 

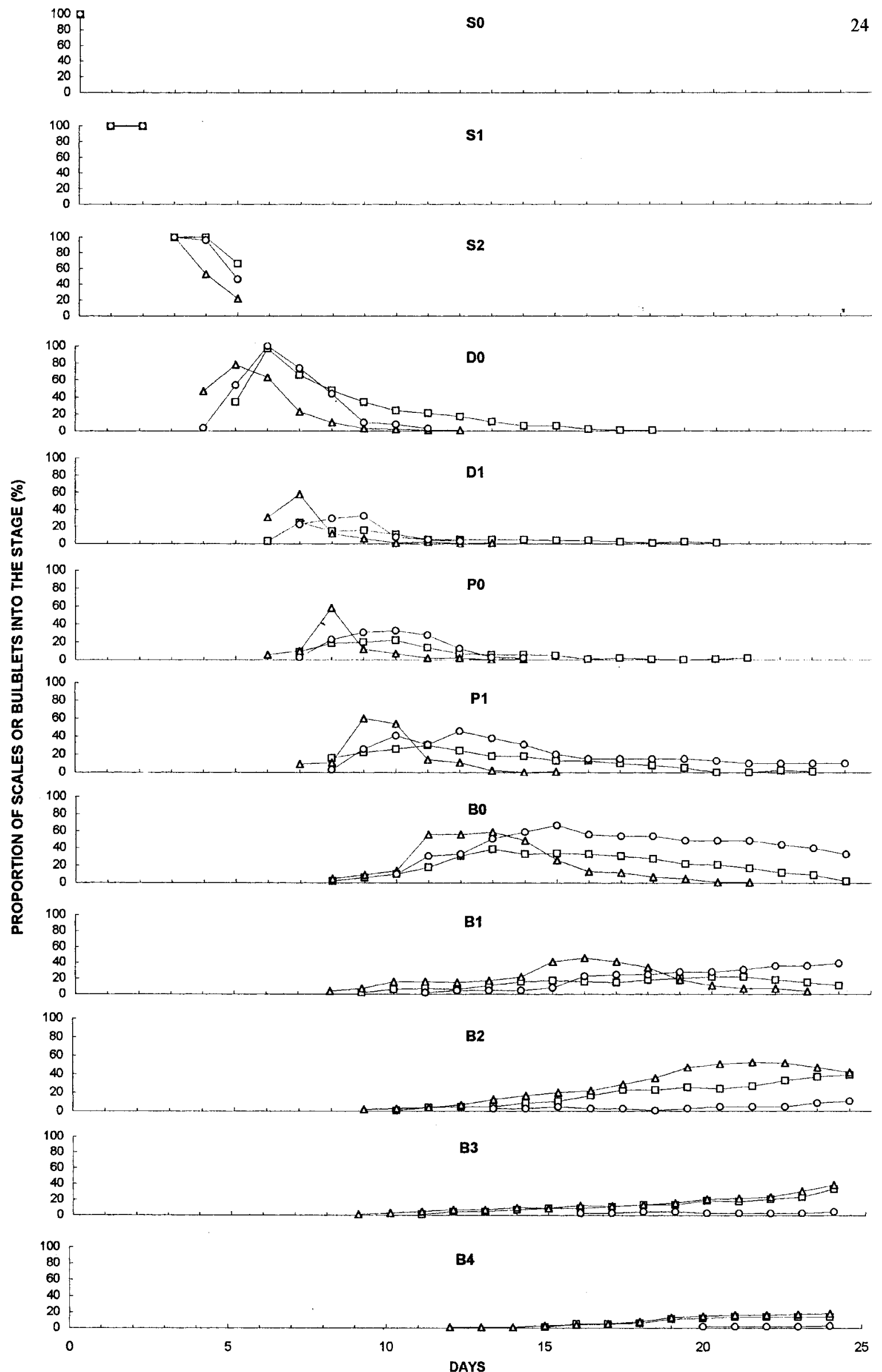

Fig. 5. Bulblet differentiation over $24 \mathrm{~d}$ from external (ם), middle $(\Delta)$ and inner $(\mathrm{O})$ scales of Lilium longiflorum. Values are expressed as a percentage of scales or bulblets at the given times (days) for each developing stage. 


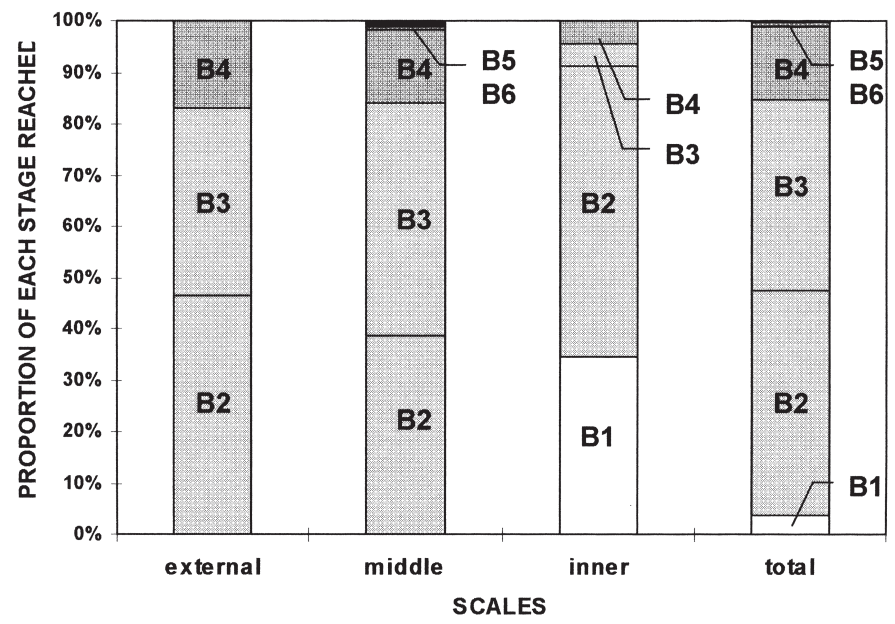

Fig. 6. Bulblet development stages ratios obtained with different types of scales at the time of bulblet harvesting (day 30). See stages description in Table 3.

A lag was observed in the appearance of stage $\mathbf{D}$ and subsequent stages of the inner scales, and a low ratio of bulblets reached $\mathbf{B}_{3}$ and $\mathbf{B}_{4}(5 \%$ and $3 \%$, respectively). More of the inner scales maintained bulblets at an earlier stage of development, even at the primordium stage, and a large quantity produced no viable bulblets. Inner scales also showed a compression of stages in time (Fig. 5).

The ratio of stages reached by bulblets detached from the mother scale at the end of the experiment (day 30) is shown in Fig. 6. Only the harvested bulblets that would better represent the scaling technique for Lilium propagation are shown. Differences between values in Fig. 6 and percentage values reached at day 24 (Fig. 5) come from considering in this last the total number of bulblets differentiated, including those little bulblets and even the primordia.

In Fig. 5 it can be observed that, for a specific day, from day 10, middle scales always had the more advanced stage, indicating that the younger (middle) scales regenerate bulblets more rapidly than older (external) ones. Moreover, middle scales produced a higher proportion of bulblets in advanced stages, i.e., B3 and higher, in comparison with external scales (Fig. 6). This ontogenic difference is not resembled in the number of bulblets produced by each kind of scale. This was significantly different $(P \leq 0.01)$ : $2.6,2.2$, and 1.2 for external, middle, and inner scales, respectively. Takayama and Misawa (1980) reported that, in vitro, younger scales produce bulblets more quickly than older ones. Van Aartrijk et al. (1989) suggested that the dormant state rather than the age of the tissue could be responsible of this phenomenon. Our findings support this idea, but also the precocity of middle scales could be attributed to a higher food content.

Inner scales produced bulblets with significantly smaller diameters, $2.1 \mathrm{~mm}$, and fresh and dry weight, 12.8 and $3.4 \mathrm{mg}$, respectively, than those measured in bulblets from middle and external scales: bulblet diameter 4.0 and $4.1 \mathrm{~mm}$, respectively, fresh weight 52.8 and $51.8 \mathrm{mg}$, respectively, and dry weight 14.7 and $13.0 \mathrm{mg}$, respectively.

Matsuo and Van Tuyl (1986) reported that external and middle lily scales produced more bulblets than inner scales, and Magnani and coworkers (1990) obtained similar results for several Lilium cultivars. They observed that the number of produced bulblets decreased from external to inner scales, and also found a positive correlation between the width of the scale base and the number of bulblets developed. According to ourobservations, in L. longiflorum 'Snow Queen', external scales had wider bases than middle scales and the bases of middle scales were wider than those of the inner scales. In coincidence, we found that bulblet yield was larger on external and middle scales than on inner ones.

Our findings demonstrate that middle scales are the ideal starting material for experiments involving scaling and, probably, in vitro propagation too. Thus, middle scales offer an appropriate material considering their higher fresh and dry weight and height together with their constancy in number. Besides, they account for half of the scales of a bulb. On the other hand, for horticultural applications or production purposes, the external scales, in addition to the middle scales, must also be used for propagation because they have a higher multiplication potential.

\section{Literature Cited}

Green, P.B. and P. Linstead. 1990. A procedure for SEM of complex shoot structures applied to the inflorescence of snapdragon (Antirrhinum). Protoplasma 158:33-38.

Hanks, G.R. 1985. Factors affecting yields of adventitious bulbils during propagation of Narcissus by the twin-scaling technique. J. Hort. Sci. 60:531-543.

Hernandez, L.F. and P.B. Green. 1993. On the transductions for expression of pattern: Biophysical analysis in sunflower (Helianthus annus L.). Plant Cell 5:1725-1738.

Magnani, G., F. Malorgio, and B. Mori. 1990. Osservazioni e ricerche sulla moltiplicazione da scaglie del Lilium. Colture Protette 3:61-68.

Marc, J. and J.H. Palmer. 1981. Photoperiodic sensitivity of inflorescence initiation and development in sunflower. Field Crops Res. 4:155-164.

Matsuo E. and J.M. Van Tuyl. 1986. Early scale propagation result in forcible bulbs of Easter lily. HortScience 21:1006-1007.

Matsuo, E., A. Nonaka, and K. Arisumi. 1987. Some factors influencing the type of leaf development (plant type) of scale bulblets of Easter lily, Lilium longiflorum. Bul. Fac. Agr., Kagoshima University, Japan.

Miller W.B. 1992. Lily biology, p. 5-8. In: A.M. Armitage (ed.). Easter and hybrid lily production. Timber Press, Portland, Ore.

MillerW.B. 1993. Lilium longiflorum, p. 391-422. In: A. De Hertogh and M. Le Nard (eds.). The physiology of flower bulbs. Elsevier, Amsterdam.

Ott, L. 1984. An introduction to statistical methods and data analysis. $2^{\text {nd }}$ ed. PWS Publ., Boston.

Roberts, A.N., J.R. Stang, Y.T. Wang, W.R. McCorkle, L.R. Riddle, and F.W. Moeller. 1985. Easter lily growth and development. Ore. State Univ. Agr. Expt. Sta. Tech. Bul. 148.

Schneiter A. and J. Miller. 1981. Description of sunflower growth stages. Crop Sci. 21:901-903.

Takayama, S. and M. Misawa. 1979. Differentiation in Lilium bulbscales grown in vitro. Effects of various cultural conditions. Physiol. Plant. 46:184-190

Tottman, D.R., R.J. Makepeace, and H. Broad. 1979. An explanation of the decimal code for the growth stages of cereals, with illustrations. Ann. Appl. Biol. 93:221-234.

Van Aartrijk, J., G.J. Blom-Barnhoorn, and P.C.G. Van der Linde. 1989 Lilies. In: P.V. Ammirato, D.A. Evans, W.R. Sharp, and Y.P.S. Bajaj (eds.). Handbook of plant cell culture. vol 5. Ornamental species. McGraw-Hill, New York.

Yanagawa, T. and Y. Sakanishi. 1980. Regenerative studies on excised bulb tissue of various tunicated bulbous ornamentals. II. Morphological observations on bulblet formation from scale segments. J. Jpn. Soc. Hort. 49:119-126. 